\title{
A Comparison of Traditional and Modern Louvers in Warm and Dry Climate
}

\author{
Hamed Hayaty*, Forough Yar Ahmadi, Abbasali Mahdian Marani \\ Department of Architecture, Ahvaz Branch, Islamic Azad University, Ahvaz, Iran \\ Email: "hamedhayaty@yahoo.com
}

Received 15 June 2016; accepted 7 August 2016; published 11 August 2016

Copyright $(\underset{2016}{ } 2 \mathrm{by}$ authors and Scientific Research Publishing Inc.

This work is licensed under the Creative Commons Attribution International License (CC BY). http://creativecommons.org/licenses/by/4.0/

(c) (i) Open Access

\begin{abstract}
Since 250 years ago i.e. when industrial revolution made human extract and exploit non-renewable energy sources rapidly, dependence on these energy sources has increased. Despite the important role of these sources of energy in mankind progress, their destructive impacts on human life should be considered and traditional environment saving methods have been proposed again. In the old ages, buildings were constructed corresponding to their climate and environment. However, after emergence of modern architecture, everything changed environmental elements which made life beautiful, like wind, sunlight and rain and dependence on mechanical ventilation systems increased rapidly. Therefore, it is clear that traditional solutions should also be changed along with modern considerations, just as traditional louvers have been replaced by modern solar louvers. This study deals with an important ventilation element i.e. traditional louver in warm and arid areas and the way it has been changed and applied in contemporary buildings.
\end{abstract}

\section{Keywords}

Ventilation, Wind, Traditional Louver, Modern Louver

\section{Introduction}

Before industrialization of architecture, people in warm areas relied only on wind as a ventilation and cooling element. "Malkaf" which literally means "wind-catcher" was invented by ancient Egyptians about 1300 years B.C. This structure performed based on pressure difference around a building and the convection resulted from chimney effect on air movement. A louver (the altered form of Malkaf) has been common for thousands of years in Iran and Persian Gulf states and has been the most effective architectural element in reduction of temperature. Louvers differ in dimensions, external shape, direction of popups and in relation with water stores in different

${ }^{*}$ Corresponding author. 
regions.

\section{Research Hypothesis}

H1: Use of innovative ideas of traditional architecture and its combination with modern buildings save nonrenewable energy sources without harming the environment.

\section{Research Methodology}

Every scientific research requires an appropriate research methodology. Selection of an appropriate research methodology is an important element in scientific study. In order to answer the research question properly, we gathered data from books, journals, papers, and websites.

\section{Wind}

Wind is an important element for architects and influences "thermal comfort" to a large degree, either by convection or by penetrating into a building. A good understanding of wind behavior especially local situations of wind influences a building construction [1].

\section{Use of Wind Flux in Architecture}

In climatic architecture, wind is used for natural ventilation of buildings. Moreover, wind can be used for cooling buildings in warm seasons and in warm areas. Of course, it should be noted that avoiding unwanted winds and controlling them is also an important subject [1].

\section{Cooling}

Wind flux can accelerate heat exchange between body and air using convection process and therefore contribute to cooling [1].

Natural cooling and ventilation:

Penetration and flux of environmental air in internal spaces of a building is called natural ventilation. This kind of ventilation increases oxygen gas and reduces carbon dioxide and odors in a building [1].

\section{Ventilation}

Natural ventilation means use of internal air movement process in a building by means of fresh air from outside, without any utilization of mechanical instruments which result in saving fossil energies consumption. In this process, the air inside the building which has become heavy and nasty as a result of breathing, skin respiration, cooking-related odors and smoking can be substituted by fresh air from outside [2].

\section{Ventilation by Means of Driving Force}

Use of wind for ventilation is possible in two ways. In the first method, same-level openings (transverse ventilation or Kouran) are used in differential elevation. In the second method, we use different-level ventilation (windcatcher or louver) in which two different elevation levels are used [2]. If openings are placed in a level, the best ventilation is possible when popups are placed on two opposite fronts (Figure 1, Figure 2).

Second-type ventilation takes place when the building has two popups on two adjacent fronts. The minimum ventilation is related to a building with two popups on a front, of course as long as a pressure difference is created by elevation difference or vertical blades between the two popups (Figure 3, Figure 4).

When openings are placed on two different levels, wind is guided through the building from the higher openings and exits the building from the other opening [2].

\section{Ventilation by Means of Thermal Driving Force (Convection Flow)}

Ventilation using convection flow or air displacement means establishment of air flux from a high-pressure environment to a low-pressure one. In this case, popups should be located in two regions with different tempera- 


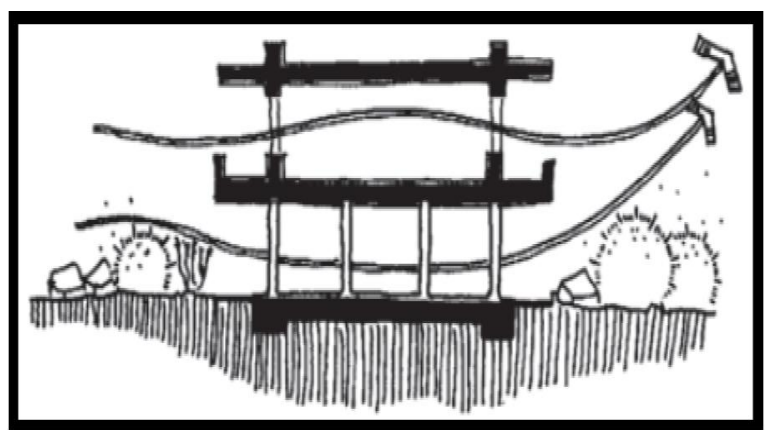

Figure 1. First method: creation of air Kouran using two windows [1].

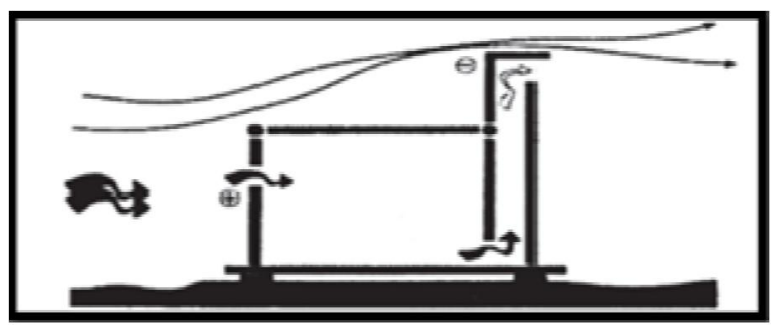

Figure 2. Second method: establishment of air flow using a window and a vertical open-ceiling channel [1].

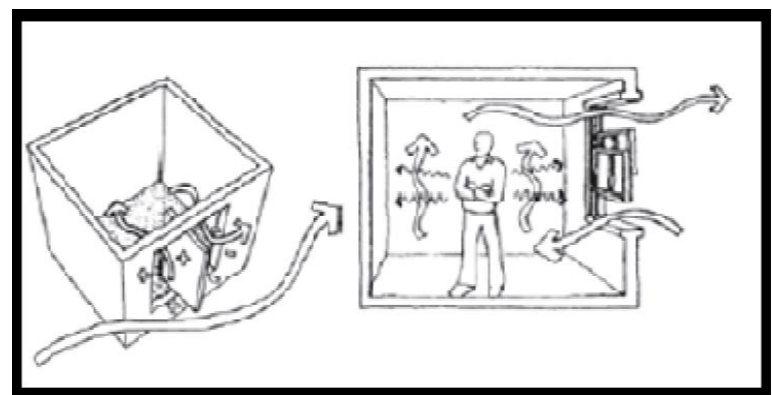

Figure 3. Establishment of limited air flux using two windows on a wall [2].

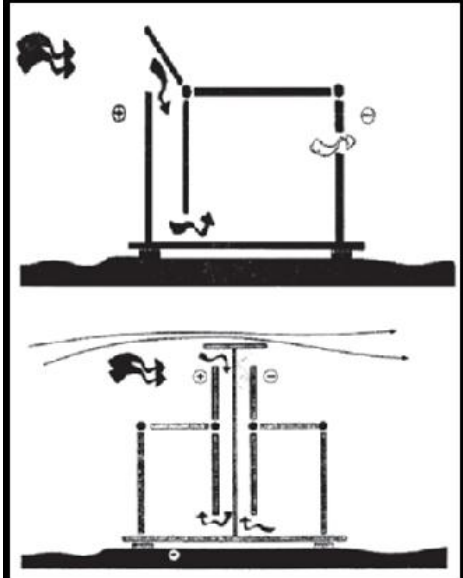

Figure 4. Influx of air from top of building and via a vertical channel and its exit from another channel or window [1] [2]. 
tures and pressures. Of course this flow is not as strong as wind force (it is a breeze actually) [1] [2]. Differential temperature between inside and outside the building, two open-ceiling and closed-ceiling regions and different areas of a building make air flow. Presence of popups in the top part of a space makes the warm air accumulated below ceiling exit and it is replaced by lower levels air. The relative vacuum created in the lower part of the space absorbs the external air via lower popups. A great differential elevation between two popups creates a differential pressure between the two levels and this results in air flux from high-pressure to low-pressure area. This feature is called chimney property. Elements like ventilator and wind-catcher have been developed for using chimney property i.e. evacuation of internal air and its substitution by outside air [1] [2]. A kind of windcatcher called spinning wind-catcher has been designed within the recent years in order to exploit this feature. It adds to energy and speed of exiting air flow rate without using electricity and only by means of installing a fan in the end of wind-catcher exit. In order to strengthen ventilator impact we can use the heat accumulated in wall of wind-catcher as a result of direct sunlight. Wall of wind-catcher warms as a result of direct sunlight and gradually the air inside wind-catcher is also warmed and it goes up with a higher speed [2] (Figure 5).

\section{Cooling by Means of Evaporative Cooling Property}

In addition to ventilation and cooling by means of substitution with cool air instead of warm air, wind can be combined with evaporative cooling and accelerate cooling process. In this process, heat is required for evaporation of water from top of wet surfaces. The main part of this heat is supplied from air which is adjacent to wet surface. Therefore, if wind flow passes past such wet surfaces, its warmth is spent on evaporation and wind cools down. A building's ventilation is cooler when an air flow is cooled by means of this process [1].

\section{Traditional Louver}

It is difficult to find about the exact background of louvers (altered form of Maklafs) because this structure has served as the highest and tallest part of buildings and the first part which destroyed in a building in the past was top elements (such as louvers). The simplest form of louvers has been found in Peru natives (Muchika native Americans). They ventilated their houses using louvers. The fact that the antiquity of wind-catchers goes back to pre-Islam Iran history has been a very difficult issue. The first historical document related to Iranian louvers goes back to the fourth millennium B.C. what is important about louvers is that these innovative Iranian traditional architectural elements are being consigned to oblivion. A louver plays an important role in directing wind flow through a building and use of natural energy in moderation of temperature and comfort. Louvers can be seen in the form of vertical channels on rooftops of buildings in warm and arid or warm and humid areas and are considered as the tallest points of buildings after tops of mosques [3].

Two factors have caused louvers construction instead of simple use of windows and doors. The first factor is that in arid areas, wind close to earth is accompanied by dust. The second is that presence of numerous windows results in sunlight massive penetration into buildings. Traditional louvers were thin tall four-, six-, or 8-dimen-

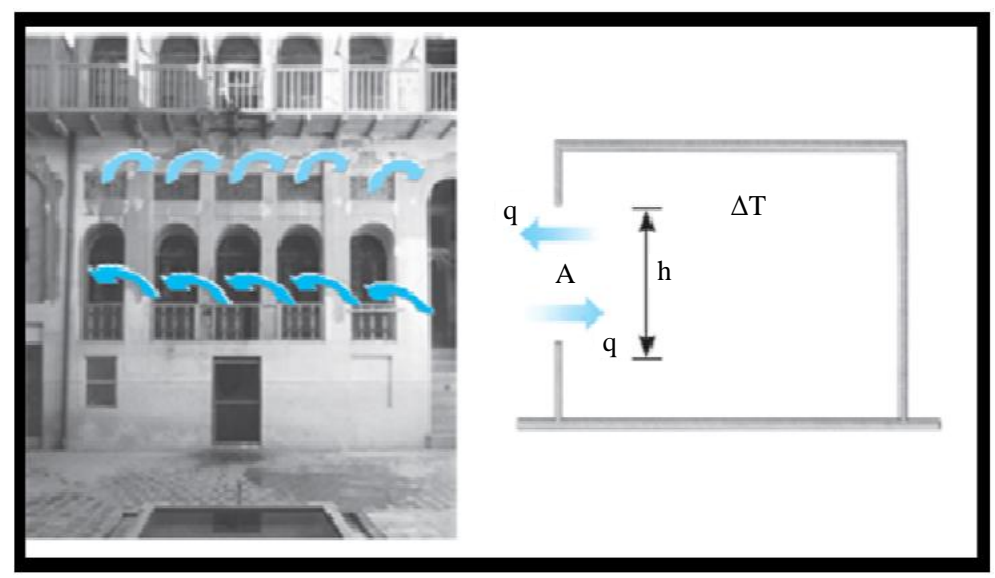

Figure 5. The role of differential temperature in the air adjacent to ceiling and bottom of a space in creation of breeze [2]. 
sional structures which were built on rooftops and besides doom-like rooftops of water stores. They were used for ventilation of water stores, internal spaces of buildings and also cellars in Iranian arid areas [3] [4].

\section{A Louver's Constituting Elements}

- Cage: it is the top of louver which contains air passing conduits.

- Stem: it is the part of the louver's body which is between cage and rooftop.

- Blade: blades are triangular elements made of brick or clay which divide louver's channel into several smaller channels.

a. main blade: walls which are stretched to the center of tower and divide the channel of louver into several smaller channels.

b. subsidiary blade: walls which are not stretched to the center of the tower and they advance to the width of external walls. These subsidiary blades are like a cooler's channel blades in the face of louvers.

- Open and closed holes: every space which is located between two blade (whether main or subsidiary) in the face of louvers is called hole. If it is open and it can pass air, it is called an open hole, otherwise, it is a closed hole [4] [5].

\section{Performance of Traditional Louvers}

There are two basic performances regarding the way of louvers' performance: a). performance based on principle of pull of openings facing wind and suction of openings which do not face wind; b). differential temperature-based performance.

a). Performance based on principle of pull of openings facing wind and suction of openings which do not face wind.

Pirnia, in his book "familiarity with Islamic architecture in Iran", explains a louver's performance as follows: "a louver performance is based upon the principle that wind blow is used for pushing fresh air into a building and its reaction force i.e. absorption is used for propelling out warm and polluted air. Maybe it is not necessary to explain that because wind hits a barrier or the very internal blades of louver it does not have any alternative but to fall, but it should be mentioned that other openings of the louver which have their backs to the wind flow direction act like a sucker instrument and send out polluted and warm air [6] (Figure 6).”

b). Based on differential temperature

Another way of performance of a louver is that air flow enters internal space of a building via windows and doors and then enters the room below louver or the pool of the building and then it goes out through the louver. In this case, the louver acts like a chimney and sucks out the air inside rooms. If there is no air flux at night, because the louver stores thermal energy during daylight, it starts thermal exchange with its surroundings. Consequently, its surrounding air warms up and moves up. Because of the pressure difference created, the internal building space air is sucked outside through the louver. Therefore, it ventilates and spins air in the internal environment of building. Furthermore, if there is no air flux in the morning, because the louver has exchanged heat

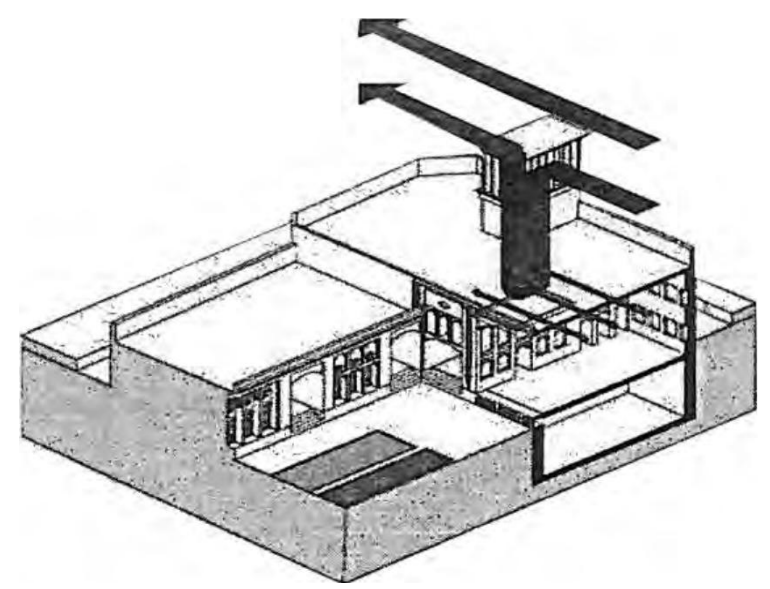

Figure 6. A louver's performance (Mahmoudi, 2009). 
with its surroundings at night, some cooling energy is stored in louver and some cool air enters the internal space of the building as a result of buoyancy force [6].

\section{Some Defects of Traditional Louvers}

Traditional louvers had the following defects and these defects can be eliminated by means of new technologies: 1. dust, insects and even small birds may enter building.

2. some part of air which enters a louver may exit from other openings and never enters the building. Of course this problem is not present in louvers which make use of only one opening for wind entrance.

3. Cooling energy which can be saved in the structure of louver is limited because the mass and specific heat of construction materials used in the louver are relatively low and this amount of energy cannot provide cooling requirements of a warm summer day. Moreover, the surface exposed to air flux may not be adequate for high amounts of heat transfer.

4. a louver does not apply to areas with low wind speed [5] [6].

\section{Modern Louvers}

In industrial building construction, louvers have been known as reliable and effective elements for using wind energy. In designing these structures, it has been tried to make use of the structure and experience of traditional louvers and wind-catcher and consider their defects to create modern elements with less problems [7]

\section{Performance}

Modern louvers do not have any moving parts and make use of vertical holes and make the wind enter a room and exit the polluted air out based on natural effects of wind and displacement of cool and war air. This system is also based on the simple rules in traditional louvers in which warm and light air moves upwards and this reduces pressure in a room and sucks air and makes it possible for cool and warm air to move [6] [7].

In commercial, administrative and... buildings, endangering security as a result of open popups is very important. This issue can be avoided by installing windows made of stainless steel inside louvers [6].

\section{Use of Floors}

Modern louvers have been designed in a way that contributes to ventilation of spaces in several floors in tall buildings. The system installed in ANS faculty in New Jersey USA serves three floors simultaneously. This has become possible using guiding blades and compass-like blades for internal division. Thus, spaces in different floors and with different distances use the same amount of air flow [6] [7].

\section{Shape and Design}

Considering the fact that use of these louvers affect building design to a large extent, builders preparations differ based on customers' ideas and shapes they prefer. Although this means difficulty of work for builders, it has facilitated use of louvers.

Use of modern louvers has another advantage and that is use of natural light as a result of openings in ceiling for ventilation. This system can be called modern photoconductive or bright. We introduce it in small details in this section [7].

\section{Modern Photoconductive System}

Mond Right Company has introduced a very useful system called bright since 1987. This system works based on solar pipes which reflect natural and renewable solar energy and even strengthen weak lights in daylight and guides it inside building using special silver-covered pipes.

\section{Material and Performance}

This system works based on mirror features. Highly reflective aluminum pipes which have become strong until 10 years by Electrolysis method have been covered by a layer of PVD which highly controls ultraviolet radiation 
to a large degree and insert natural and harmless light into a building. The upper part of bright is made of polycarbonate and is moisture-insulator and prevents from entrance of dust and darkening of mirror surfaces and makes this system efficient in solar, cloudy and even rainy conditions.

The modern photoconductive system has a control panel just like modern louvers and the light inserted can be controlled. This system is produced in 400 - 1500 millimeters sizes and in square and circular shapes.

Undoubtedly, use of this integrated ventilation and lighting system contributes to saving energy in summer which requires a lot of energy for cooling, ventilation and lighting of spaces [4].

\section{Sound Transfer}

Sound pollution is an issue which can be minimized by closing doors and windows in buildings with fresh and cool ventilation. In January 2002 and December 2005, modern louvers' system was sent to acoustic test center (BRE) in USA. In comparison with global standards, modern louver's sound transfer is 26 units smaller than an open window. By adding a 15 millimeter acoustic cover to internal body of the instrument, this average increases by 10 units and becomes closer to the favorable number [7] (Figure 7).

\section{Use in Different Seasons and Fire}

In order to be used in different seasons, this system is equipped with special dampers which consume a small amount of energy and control air influx. There are four modes: spring, summer, winter and autumn on the control panel. By selecting each of these modes and by means of a barometer and carbon dioxide amount control in air, the inlet and outlet of air and pollutants can be controlled easily and they can be changed besides smart system. This amount is $100 \%$ in summer and 3 - 5 percent in winter only for ventilation. Dampers of air inlet control act also in fire cases. They become closed in fire cases as a result of smart relationship with fire announcement system in the building and also stop air inlet to fire and block louver from acting as a fire tunnel and its spread to other floors [6].

\section{Problems of Using Louvers in Contemporary Buildings}

Today, because of paying attention to sustainable architecture and designing green buildings, it is possible and useful to investigate and use louvers in buildings. Since these louvers are based on traditional louvers, their construction has brought in some problems some of which have been accompanying this structure from past and some others are resulted from modern life.

One of the greatest problems is controlling inlet air in different seasons and its amount in peak seasons which made people to build separate spaces for living in summer and winter in the past. Entrance of dust and other pollutions like sound pollution especially in buildings in which sound pollution control is of great importance

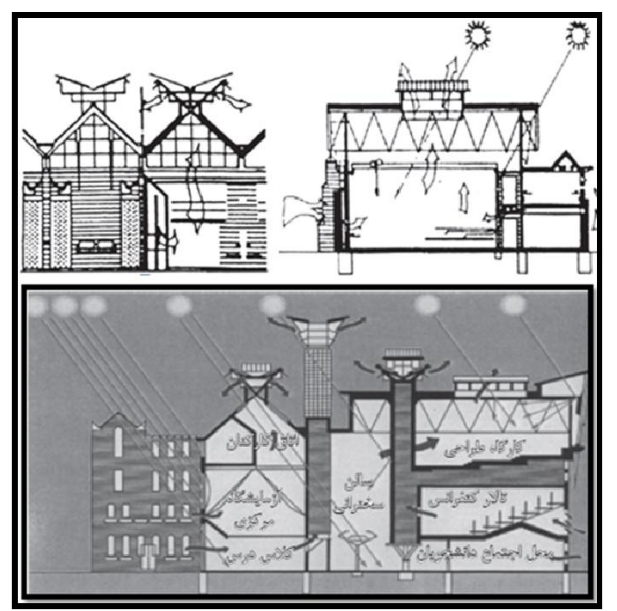

Figure 7. Installation of numerous popups for inserting air into a building and preparation of different types of ventilator for its exit [1]. 
(like libraries, hospitals, conference saloons.....) is another problem.

Another issue is that louvers should be designed such that they do not contribute to fire spreading and they control smoke to outside of the building.

Finally, numerous openings in ceiling bring security issues. It should be noted that use of louvers has made great changes in architecture, form and structure of buildings and its matching with modern tastes and architecture should be discussed. Many studies have been conducted in this regard and many solutions have been also proposed. Modern louvers are good solutions and substitutes for traditional ones which were discussed in this paper [4].

\section{Conclusion}

By understanding wind features, they can be applied in architecture in three ways: cooling, natural ventilation and controlling winds. To this end, we should first identify wind performance and its behavior towards barriers and passing through them. What was mentioned and discussed in this study is one of the hundreds of innovative architectural ideas propounded by making over ages without harming the environment. These solutions are plain and meanwhile renewable. Fossil fuels consumption can be declined by using traditional ventilation systems and its combination with new systems. This contributes to environment protection.

\section{References}

[1] Rah Shahr International Group (2011) The Role of Architecture Design in Reduction of Energy Consumption in Buildings (Wind Energy in Architecture). No. 129.

[2] Pirnia, M.K. (2004) Familiarity with Islamic Architecture (Edited and Prepared by Gholam Hosein Memarian). Memar. Press, Tehran.

[3] Bahadori Nejad, M. and Dehghani, A.R. (2008) Louver, Masterpiece of Iranian Engineering. University Press, Iran.

[4] Khamoushian, N. (2011) Modern Louvers. Architect, 68, 113.

[5] Raoufi Rad, M. (2006) Design of Solar Systems in Buildings in Iran. Fadak Isatis Publications, Tehran.

[6] Mahmoudi, M. (2009) Louver, the Symbol of Iranian Architecture. Yazda, Tehran.

[7] Mahmoudi, M. and Mofidi, M. (2008) An Investigation of Typology of Louvers Design in Yazd and Finding Optimum Functional Type. Journal of Fine Arts, 36, 27.

\section{Submit or recommend next manuscript to SCIRP and we will provide best service for you:}

Accepting pre-submission inquiries through Email, Facebook, LinkedIn, Twitter, etc.

A wide selection of journals (inclusive of 9 subjects, more than 200 journals)

Providing 24-hour high-quality service

User-friendly online submission system

Fair and swift peer-review system

Efficient typesetting and proofreading procedure

Display of the result of downloads and visits, as well as the number of cited articles

Maximum dissemination of your research work

Submit your manuscript at: http://papersubmission.scirp.org/ 